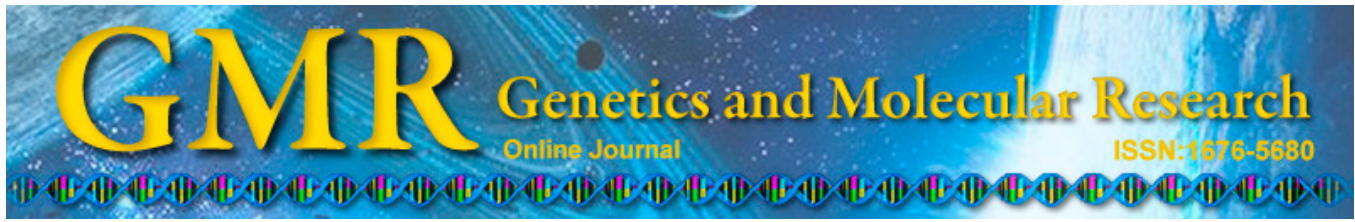

\title{
Effect of $Z N F 217$ gene polymorphisms on colorectal cancer development in a Mexican population
}

R. Ramírez-Ramírez ${ }^{1}$, M. Gutiérrez-Angulo ${ }^{1,2}$, M.T. Magaña ${ }^{3}$, J.M. Moreno-Ortiz ${ }^{1}$, M. Partida-Pérez ${ }^{1}$, R. Muñiz-Mendoza ${ }^{1}$, J. Peregrina-Sandoval ${ }^{4}$, A.S. Suárez-Villanueva ${ }^{1}$, M. Centeno-Flores ${ }^{5}$, V.M. Maciel-Gutiérrez ${ }^{5}$, E. Cabrales-Vazquez ${ }^{6}$ and M.L. Ayala-Madrigal ${ }^{1}$

${ }^{1}$ Instituto de Genética Humana and Doctorado en Genética Humana, CUCS, Universidad de Guadalajara, Guadalajara, Jalisco, México ${ }^{2}$ Departamento de Clínicas, CUAltos, Universidad de Guadalajara, Jalisco, México

${ }^{3}$ División de Genética, CIBO, IMSS, Guadalajara, Jalisco, México

${ }^{4}$ Laboratorio de Inmunobiología, CUCBA, Universidad de Guadalajara, Zapopan, Jalisco, México

${ }^{5}$ Servicio de Colon y Recto, “Juan I. Menchaca” Hospital Civil, Guadalajara, Jalisco, México

${ }^{6}$ Servicio de Oncología "Fray Antonio Alcalde" Hospital Civil, Guadalajara, Jalisco, México

Corresponding author: M.L. Ayala-Madrigal

E-mail: ayama1624@yahoo.com.mx

Genet. Mol. Res. 14 (1): 362-367 (2015)

Received January 2, 2014

Accepted April 8, 2014

Published January 23, 2015

DOI http://dx.doi.org/10.4238/2015.January.23.9

\begin{abstract}
The ZNF217 gene, a potential oncogene amplified and overexpressed in several cancers including colorectal cancer (CRC), acts as a transcription factor that activates or represses target genes. The polymorphisms rs16998248 (T>A) and rs35720349 (C>T) in coronary artery disease have been associated with reduced expression of ZNF217. In this study, we analyzed the 2 polymorphisms in Mexican patients with CRC. Genotyping of rs 16998248 and rs35720349 sites
\end{abstract}


was performed by polymerase chain reaction-restriction fragment length polymorphism in 203 Mexican Mestizos, 101 CRC patients, and 102 healthy blood donors. Although no statistical differences regarding genotype and allele frequencies of ZNF217 polymorphisms were observed $(\mathrm{P}>0.05)$, linkage disequilibrium was significant in CRC patients $\left(\mathrm{r}^{2}=0.39, \mathrm{P}<0.0001\right)$, as a result of reduced AC haplotype frequency. Thus, the AC haplotype may protect against CRC.

Key words: Colorectal cancer; rs16998248; rs35720349; ZNF217

\section{INTRODUCTION}

Colorectal cancer (CRC) is the third most common cancer in men and the second most common cancer in women worldwide (Jemal et al., 2011). Genetic susceptibility to CRC is associated with genes related to proliferation, differentiation, and cell transformation processes. These genes include KRAS, CDH1, TGF- $\beta$, and ZNF217 (Kerr, 2003; Rooney et al., 2004). The ZNF217 oncogene spans over $16 \mathrm{~kb}$ of chromosome 20q13.2, where it contains 5 exons and encodes 2 open reading frames of 1062 and 1108 amino acids produced through alternative splicing of exon 4 (Yaswen and Collins, 2005). ZNF217 functions as an activator of genes such as BRCA1, $C D C 25 C, T U B B 2$, and $L M N B 1$ and as a repressor of genes such as $C D H 1, p 15$, and VAV3 (Cowger et al., 2007; Thillainadesan et al., 2008). Gene amplification and/or overexpression of ZNF217 have mainly been described in breast, ovarian, gastric, and colon cancers (Quinlan et al., 2007). A total of $61 \%$ of patients with colon cancer show amplification, particularly advanced adenomas and carcinomas (Rooney et al., 2004). Moreover, ZNF217 protein expression is directly related to the number of amplified copies in ovarian clear cell carcinoma (Rahman et al., 2012).

At least 2 single nucleotide polymorphisms (SNPs) in the ZNF217 gene, rs 16998248 (exon 2, T>A, corresponding to the change of A342A) and rs35720349 (exon 4, C>T, corresponding to change I548T), have been described previously (dbSNP, 2013). These polymorphisms have been associated with reduced expression of the ZNF217 protein in coronary artery disease (CAD) (Wang, 2009).

In this study, we analyzed the rs 16998248 and rs35720349 polymorphisms in CRC patients in Western Mexico. This is the first study to evaluate the potential role of these variants in cancer.

\section{MATERIAL AND METHODS}

The study included 203 Mexican Mestizos, 101 CRC patients, and 102 healthy blood donors recruited at the Fray Antonio Alcalde and Juan I. Menchaca Hospitals of Guadalajara, Mexico. All individuals signed an informed consent and the study was approved by the Research, Ethics, and Safety Committees of Centro Universitario de Ciencias de la Salud, Universidad de Guadalajara (CI-14409).

Genomic DNA was obtained from peripheral blood using the CTAB/DTAB method (Gustincich et al., 1991). Analysis of ZNF217 variants was performed by polymerase chain reaction (PCR)-restriction fragment length polymorphism analysis with primers designed using the Oligo v.6.0 software. For SNP rs 16998248, the forward primer 5'-AGTCTAATTGAG CACCGCAAGG-3' and reverse primer 5'-TGAAAGCTTTGCCGCACTC-3' were used to 
amplify a 466-bp fragment. PCR cycling conditions were as follows: initial denaturation at $94^{\circ} \mathrm{C}$ for $10 \mathrm{~min}$ followed by 38 cycles of denaturation at $94^{\circ} \mathrm{C}$ for $1 \mathrm{~min}$, annealing at $63.3^{\circ} \mathrm{C}$ for 1 min, extension at $72^{\circ} \mathrm{C}$ for $1 \mathrm{~min}$, and a final elongation at $72^{\circ} \mathrm{C}$ for $5 \mathrm{~min}$. Restriction enzyme digestion with $S t u \mathrm{I}$, which recognizes the wild-type T allele, resulted in fragment sizes of 341 and $125 \mathrm{bp}$. PCR for rs 35720349 was conducted under the same conditions except that 35 cycles were used, annealing was conducted at $57.2^{\circ} \mathrm{C}$, and the following primers were used: forward, 5'-TTAGGTGAAAAACCATACAA-3' and reverse, 5'-GGACTGCCTGTAACATCT-3' (PCR fragment of $233 \mathrm{bp}$ ). For restriction analysis, the AseI enzyme cut the PCR product at the polymorphic $\mathrm{T}$ allele to produce fragments of 160 and $73 \mathrm{bp}$. Visualization of fragments was achieved on $6 \%$ polyacrylamide gels stained with silver nitrate.

Genotype and allele frequencies were determined by direct counting. Frequency differences between CRC patients and controls as well as the odds ratios (ORs) with the $95 \%$ confidence intervals $(95 \% \mathrm{CIs})$ were analyzed using the website [http://ihg.gsf.de/ihg/snps.html]. Haplotypes were determined directly in homozygous or single-site heterozygous individuals. When individuals showed both heterozygous sites, the gametic phase was assigned using the Bayesian algorithm. Linkage disequilibrium (LD) between the polymorphisms was evaluated with haplotype data using a test of allele correlation $\left(\mathrm{r}^{2}\right)$; results were considered statistically significant when $r^{2} \geq 0.33$ (Shifman et al., 2003). One million steps of Markov chain length were considered. The Ewens' sampling distribution test was used to predict the expected haplotypes in CRC patients (Ewens, 1972). Statistical analyses were performed using the Arlequin v.3.11 software (Excoffier et al., 2005). Values were considered significant when $\mathrm{P}<0.05$.

\section{RESULTS}

The frequencies of rs16998248 (T>A) and rs35720349 (C>T) ZNF217 variants are shown in Table 1. Three genotypes were observed for each polymorphism, but the frequency of the mutated allele was lower than $10 \%$. Comparison of genotype and allele frequencies between the two studied groups showed no significant differences. However, the rs16998248 AA genotype was observed less frequently in patients than in controls ( $2 v_{s} 7.8 \%$, respectively).

\begin{tabular}{|c|c|c|c|c|c|c|}
\hline \multirow[b]{2}{*}{ rs16998248 } & \multicolumn{2}{|c|}{ Control group } & \multicolumn{2}{|c|}{ CRC patients } & \multirow[t]{2}{*}{ P value* } & \multirow[t]{2}{*}{ OR $(95 \% \mathrm{CI})$} \\
\hline & $\mathrm{N}=102$ & $\%$ & $\mathrm{~N}=101$ & $\%$ & & \\
\hline \multicolumn{7}{|l|}{ Genotype } \\
\hline $\mathrm{TT}$ & 63 & 61.8 & 64 & 63.4 & & 1.00 (reference) \\
\hline AT & 31 & 30.4 & 35 & 34.6 & 0.73 & $1.12(0.613-2.016)$ \\
\hline AA & 8 & 7.8 & 2 & 2.0 & 0.06 & $0.25(0.050-1.204)$ \\
\hline \multicolumn{7}{|l|}{ Allele } \\
\hline $\mathrm{T}$ & 157 & 77.0 & 163 & 80.7 & & 1.00 (reference) \\
\hline A & 47 & 23.0 & 39 & 19.3 & 0.36 & $0.80(0.496-1.289)$ \\
\hline rs35720349 & $\mathrm{N}=99$ & $\%$ & $\mathrm{~N}=100$ & $\%$ & & \\
\hline \multicolumn{7}{|l|}{ Genotype } \\
\hline $\mathrm{CC}$ & 87 & 87.9 & 85 & 85.0 & & 1.00 (reference) \\
\hline $\mathrm{CT}$ & 10 & 10.1 & 14 & 14.0 & 0.41 & $1.44(0.603-3.403)$ \\
\hline TT & 2 & 2.0 & 1 & 1.0 & 0.58 & $0.52(0.046-5.749)$ \\
\hline \multicolumn{7}{|r|}{ ) } \\
\hline C & 184 & 92.9 & 184 & 92.0 & & 1.00 (reference) \\
\hline $\mathrm{T}$ & 14 & 7.1 & 16 & 8.0 & 0.72 & $1.15(0.542-2.409)$ \\
\hline Haplotypes & $\mathrm{N}=160$ & $\%$ & $\mathrm{~N}=196$ & $\%$ & & \\
\hline TC & 122 & 76.3 & 160 & 81.6 & & 1.00 (reference) \\
\hline $\mathrm{AC}$ & 27 & 16.9 & 20 & 10.2 & 0.07 & $0.56(0.303-1.055)$ \\
\hline AT & 11 & 6.8 & 16 & 8.2 & 0.8 & $1.11(0.49-2.48)$ \\
\hline
\end{tabular}


Haplotypes were determined (rs16998248 T $>$ A and rs35720349 C $>$ T) for 98 CRC patients and 80 controls. Different combinations were first unambiguously determined in homozygotes and single-site heterozygotes $(88.2 \%)$ and in individuals $(11.8 \% ; 14$ patients and 7 controls) with both heterozygous sites; the phase was inferred using the Bayesian algorithm. Three distinct haplotypes were observed in patients and controls. The most common was TC, with frequencies of 81.6 and $76.3 \%$ in patients and controls, respectively (Table 1). The TT haplotype was not observed. Haplotype distribution was not significantly different between CRC patients and control individuals. LD was estimated based on haplotype frequencies, and the results showed significant LD only in CRC patients $\left(\mathrm{r}^{2}=0.39, \mathrm{P}<0.0001\right)$. Thus, we obtained the expected haplotypes in the CRC group using the Ewens' sampling distribution test (Ewens, 1972). Statistically significant differences in haplotype distribution were detected between the observed haplotypes (TC, $\mathrm{N}=160 ; \mathrm{AC}, \mathrm{N}=20$; and $\mathrm{AT}, \mathrm{N}=16$ ) and expected haplotypes (TC, $\mathrm{N}=154 ; \mathrm{AC}, \mathrm{N}=34$; and $\mathrm{AT}, \mathrm{N}=7 ; \mathrm{P}=0.026$ ). This discrepancy was likely a consequence of the significant reduction in the AC haplotype $(20$ vs $34, \mathrm{P}=0.03)$ in CRC patients.

\section{DISCUSSION}

The ZNF217 transcriptional regulation gene plays an important role in carcinogenesis. Its overexpression has been associated with the growth, proliferation, and survival of malignant cells in ovarian cancer (Huang et al., 2005; Sun et al., 2008; Rahman et al., 2012) as well as with tumor progression in the MCF7 and 600MPE breast cancer cell lines (Rahman et al., 2012).

We studied 2 polymorphisms in the ZNF217 gene, including rs16998248 (T>A) and rs35720349 $(\mathrm{C}>\mathrm{T})$. Both in CRC patients and in control individuals, mutation frequencies ranged from $1.0-7.8 \%$. Similar frequencies $(0.0-4.7 \%)$ were reported for the rs 16998248 polymorphism in the SNP database for several populations (European, African American, Sub-Saharan African, and Asian). This comparison was also conducted for the rs35720349 TT polymorphic genotype, but this polymorphism was not identified in Caucasian, African American, and European populations (http://www.ncbi.nlm.nih.gov/projects/SNP); in the present study, the frequency of this polymorphism was $2 \%$.

Wang (2009) found that in a control group of 405 healthy individuals recruited from Duke University Hospital, the frequencies of the rs 16998248 A and rs35720349 T alleles were 0.060 and 0.013 , respectively, while our results showed frequencies of 0.23 and 0.071 , respectively. These differences were significant $(\mathrm{P}<0.000)$.

In this study, no significant differences in genotype and allele frequencies were found between CRC and control groups, although the rs16998248 AA genotype showed a trend for protection against $\mathrm{CRC}(\mathrm{OR}=0.25,95 \% \mathrm{CI}=0.050-1.204, \mathrm{P}=0.06)$.

The observed trend for protection from the present study by the rs16998248 AA genotype agrees with the results of Wang (2009), who also showed that minor alleles of both coding polymorphisms reduced ZNF217 expression in aorta samples of Caucasian patients with CAD. Our results indicate that in cancer cells, these polymorphisms could cause decreased ZNF217 expression.

Because the rs16998248 $\mathrm{T}>\mathrm{A}$ polymorphism encodes a synonymous amino acid change (A342A), there is no direct effect on the protein sequence; however, this change can nonetheless modify the expression level of the gene because of the impaired translation efficiency ascribed to different tRNA pools corresponding to alternative codons coding for the same amino acid (Waldman et al., 2011). Therefore, this polymorphism may alter the ZNF217 
protein elongation rate based on differences in tRNA pools, leading to decreased expression of ZNF217 and further compromising the formation of protein complexes in which ZNF217 functions as a transcriptional regulator (Carmi et al., 2009).

$\mathrm{LD}$ analysis between the locus pair was significant in CRC patients $\left(\mathrm{r}^{2}=0.39\right)$. This LD was a consequence of a pronounced reduction in the AC haplotype ( $20 v s 34, \mathrm{P}=0.03)$. Haplotype comparison between CRC patients and control subjects revealed a slightly decreased AC combination in CRC patients $(10.2$ vs $16.9 \%, \mathrm{P}=0.07)$. Based on these results, the AC haplotype is a protective factor against $\mathrm{CRC}$. However, further studies are necessary to determine whether the AC haplotype modifies ZNF217 expression or if it is linked to a susceptibility locus.

In conclusion, allelic, genotypic, and haplotype frequencies of the rs16998248 ( $\mathrm{T}>\mathrm{A})$ and rs35720349 (C>T) polymorphisms were similar between CRC patients and control subjects. However, both polymorphisms were in LD in CRC patients as consequence of reduced AC haplotype frequency.

\section{ACKNOWLEDGMENTS}

We thank Dr. H. Rivera for reviewing the manuscript. Research supported by a COECYTJAL-UDG grant (\#PS-2009-832). R. Ramírez-Ramírez, R. Muñiz-Mendoza, and A.S. Suárez-Villanueva received PhD CONACyT fellowships.

\section{REFERENCES}

Carmi S, Levanon EY and Eisenberg E (2009). Efficiency of complex production in changing environment. BMC Syst. Biol. 3: 3-10.

Cowger JJ, Zhao Q, Isovic M and Torchia J (2007). Biochemical characterization of the zinc-finger protein 217 transcriptional repressor complex: identification of a ZNF217 consensus recognition sequence. Oncogene 26: 3378-3386.

Database of Single Nucleotide Polymorphisms (dbSNP) (2013). Bethesda (MD): National Center for Biotechnology Information, National Library of Medicine. dbSNP Accession Nos. rs16998248, rs35720349 (dbSNP Build ID: 138 Phase I). Available at [http://www.ncbi.nlm.nih.gov/SNP/]. Accessed August 1, 2013.

Ewens WJ (1972). The sampling theory of selectively neutral alleles. Theor. Popul. Biol. 3: 87-112.

Excoffier L, Laval G and Schneider S (2005). Arlequin (version 3.0): an integrated software package for population genetics data analysis. Evol. Bioinform. Online 1: 47-50.

Gustincich S, Manfioletti G, Del Sal G, Schneider C, et al. (1991). A fast method for high-quality genomic DNA extraction from whole human blood. Biotechniques 11: 298-300.

Huang G, Krig S, Kowbel D, Xu H, et al. (2005). ZNF217 suppresses cell death associated with chemotherapy and telomere dysfunction. Hum. Mol. Genet. 14: 3219-3225.

Jemal A, Bray F, Center MM, Ferlay J, et al. (2011). Global cancer statistics. CA Cancer J. Clin. 61: 69-90.

Kerr D (2003). Clinical development of gene therapy for colorectal cancer. Nat. Rev. 3: 615-622.

Quinlan KG, Verger A, Yaswen P and Crossley M (2007). Amplification of zinc finger gene 217 (ZNF217) and cancer: when good finger go bad. Biochim. Biophys. Acta 1775: 333-340.

Rahman MT, Nakayama K, Rahman M, Nakayama N, et al. (2012). Prognostic and therapeutic impact of the chromosome 20q13.2 ZNF217 locus amplification in ovarian clear cell carcinoma. Cancer 118: 2846-2857.

Rooney PH, Boonsong A, McFadyen MCE, McLeod HL, et al. (2004). The candidate oncogene ZNF217 is frequently amplified in colon cancer. Cancer J. Pathol. 204: 282-288.

Shifman S, Kuypers J, Kokoris M, Yakir B, et al. (2003). Linkage disequilibrium patterns of the human genome across populations. Hum. Mol. Genet. 12: 771-776.

Sun G, Zhou J, Yin A, Ding Y, et al. (2008). Silencing of ZNF217 gene influences the biological behavior of a human ovarian cancer cell line. Int. J. Oncol. 32: 1065-1071.

Thillainadesan G, Isovic M, Loney E, Andrews J, et al. (2008). Genome analysis identifies the p15ink4b tumor suppressor as a direct target of the ZNF217/CoREST complex. Mol. Cell Biol. 28: 6066-6077. 
Waldman YY, Tuller T, Keinan A and Rupping E (2011). Selection for translation efficiency on synonymous polymorphisms in recent human evolution. Genome Biol. Evol. 3: 749-761.

Wang T (2009). Identifying transcription factor targets and studying human complex disease genes. PhD dissertation, North Carolina State University.

Yaswen P and Collins C (2005). ZNF217 (Zinc Finger Protein 217) Atlas Genet Cytogenet Oncol Haematol. Available at [http://AtlasGeneticsOncology.org/Genes/ZNF217ID42875ch20q13.html]. 